\title{
Complete Edentulous Rehabilitation of a Down's syndrome Patient Also Being Treated for Schizophrenia - Case Report
}

\author{
Authors \\ Areej $\mathrm{AG}^{1}$, Khurshid A Mattoo ${ }^{2 *}$ \\ ${ }^{1}$ Student (UG-SDS541), College of Dentistry, Jazan University, (KSA) \\ $2 *$ Assistant professor, Department of Prosthetic dental sciences, College of Dentistry, Jazan University, \\ (KSA) \\ * Corresponding Author \\ Khurshid A Mattoo \\ Email: drkamattoo@rediffmail.com
}

\begin{abstract}
Although patients with downs syndrome are found routinely in the medical clinics, their high prosthetic treatment needs require them to seek prosthetic care. These patients are known to have psychiatric disorders, but rarely psychotic disorder like Schizophrenia is found, because of the difficulty associated to isolate the disorder as a result of downs syndrome or schizophrenia. A childish female patient came to the prosthetic undergraduate clinic seeking complete denture prosthesis. Thorough and careful history revealed the patient was under a medication regimen of 4 drugs that had a definite impact on prosthetic outcome. Difficulties during complete denture fabrication were mainly due to the hypotonia, dyskinesia, dystonia as it affected the normal mandibular movements. Besides implications related to complete denture fabrication other prosthodontic implications have also been reviewed and summarized in the discussion.

Keywords: anti-psychotic drugs, complete denture, clopixol, dyskinesia, dystonia, Xerostomia.
\end{abstract}

\section{Introduction}

Genetic aberrations in living beings are complex that often result in multiple abnormalities. Among many chromosomal human disorders, Trisomy 21 (Down's syndrome, Mongolism) is commonly observed which also causes mental retardation. Described first in $1866,{ }^{1}$ with cause established in $1959,{ }^{2}$ the syndrome in $95 \%$ of patients is due to trisomy 21 while a further $4 \%$ have translocation between all or part of chromosome 21 and another on acrocentric chromosome 14. Physical features include dysmorphology particularly face, mental features include intellectual disability, motor disorders while medical features may include cardiovascular, immunological, respiratory, neurological and musculoskeletal abnormalities. Besides these there are studies that have shown subjects with Down's syndrome are prone to develop depressive or anxiety disorders. 3,4 Schizophrenia, which is a long term mental disorder that involves a breakdown in the relation between thought, emotion and behaviour leading to faulty perception, inappropriate feelings and actions and a sense of mental fragmentation. The person has a significantly negative effect on the self-care ability of the patient which leads to poor oral hygiene as 
well as a high dental prosthetic treatment need (DPTN). ${ }^{5,6}$ investigations of the prevalence and or possible association between the two is scarce in the medical literature and are limited to case reports. ${ }^{7}$ As the treatment of schizophrenia includes antipsychotic drugs, the further add the problem to already existing DPTN.

This article in the form of a case report describes a case of complete denture rehabilitation of a young female patient suffering from Down's syndrome and was on a drug regimen for associated Schizophrenia. The article also presents prosthodontic implications of problems associated with patients suffering from Down's syndrome.

\section{Case Report}

A childish but adult female aged 28 years reported to the clinical course for undergraduate students in the course of clinical prosthodontics in the college of dentistry. The chief complaint was presented by the patient's mother and included the loss of all teeth since last 8 years and wished prosthetic replacement for her daughter. Medical history revealed that the patient has downs syndrome and has been also diagnosed with schizophrenia about seven years back and was currently under medication. Medication regimen included Ariprazole (15mg), Haloperidol (5mg), Zuclopenthixol (200mg injection) and Carbamazepine (200mg). The patient was obese and had gained weight since last five years. A thorough dental history was recorded regarding patient's previous dentition status, the presence of abnormalities in dentition, oral hygiene practices, parafunctional and functional habits. Social history about patient's family attitude towards her and her oral health was also investigated. Emphatic approach that involved elaborate appointment time, patient desensitization towards dental instruments and materials, good communication, extra care and trustful rapport was established with the patient.

Counselling of the mother regarding the limitations of complete denture and the patient's condition was regularly done during the entire course of the treatment. The patient's sister who was responsible for the majority of the patient care at home was asked to accompany the patient in future visits. Extra oral examination disclosed frontal bone bossing, unattractive facial movements, poor neuromuscular control and coordination, abnormal mandibular movements, impaired speech and a squint (Fig.1 a, b).

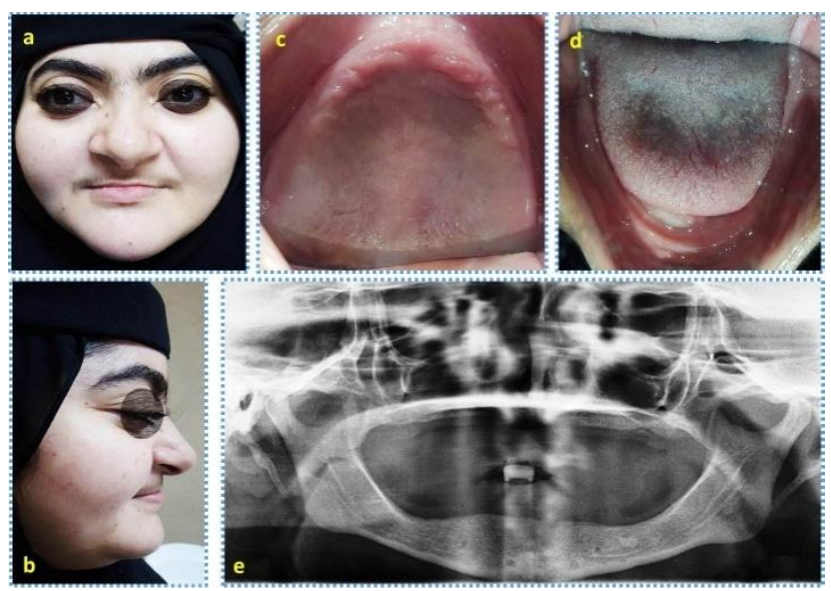

Figure 1: Extra oral view $(a, b)$, Intra oral view of the maxillary and mandibular completely edentulous arches (c,d), Orthopantomograph showing resorbed arches.
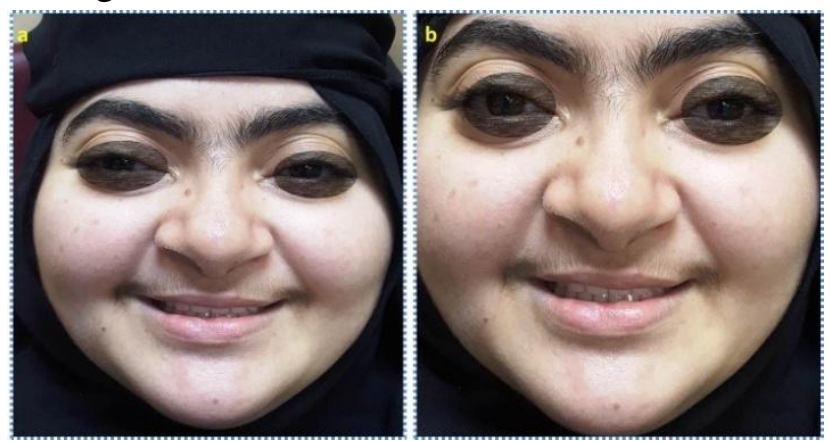

Figure 2: Extra oral view after denture insertion (a, b)

Intra oral examination revealed poorly formed residual alveolar ridges with flat palatal vault that was narrow posteriorly while mandibular ridges were wide posteriorly (Fig.1 c, d). Other treatment modifiers included macroglossia with protrusion, hyper salivation, limited mouth opening, obese intra oral environment, hyper gag reflex, poor mandibular control and patient's lack of understanding. Orthopantomograph showed poorly formed maxillary and mandibular arches with no evidence of any temperomandibular joint abnormality (Fig.1 e). Medical opinion was sought regarding her present status and the side effects of the drugs. After thorough consultation a treatment plan for complete 
denture as a prosthetic option was presented to the patient's mother and conventional complete denture was fabricated with certain necessary modifications. Primary impressions were made using impression compound (Prevest, Hiflex compound) followed by refinement of the borders at the same appointment. Routine design for special tray was applied (selective pressure theory) which was followed by the border moulding with green stick compound (Kerr). Jaw relations were established in stages. Difficulty in recording centric jaw relation was encountered by forming a trough of $1 \mathrm{~mm}$ in the mandibular anterior occlusal rim. Teeth selected were modified in dimensions before arranging them. Posterior trial was done twice before processing the denture. Clinical remount was done at the time of denture insertion. The dentures were then delivered to the patient and post care instructions were given to the patient both verbally and in a written format (Fig.2 a, b). Follow up included every week for first two months, followed by every fortnight for three months and then every month for six months.

Table 1: Prosthodontic inferences of downs syndrome

\begin{tabular}{|c|c|c|c|c|}
\hline S.no & Affected systems & Signs, symptoms, side effects & Prosthodontic implications & Solutions \\
\hline 1. & Gastro intestinal & $\begin{array}{l}\text { Acid reflux, Impaired relaxation during } \\
\text { swallowing (use of tongue as anterior seal rather } \\
\text { than lips) }\end{array}$ & $\begin{array}{l}\text { Erosion and surface } \\
\text { deterioration of acrylic resin }\end{array}$ & \multirow{10}{*}{$\begin{array}{l}\text { General } \\
\text { Thorough social history especially } \\
\text { attitude of family members, listen } \\
\text { actively, find patients functional } \\
\text { abilities, emphatic approach, more } \\
\text { clinical time, use of mediator during } \\
\text { treatment procedures, extra care, } \\
\text { desensitization of the patient to dental } \\
\text { instruments, reassurance and } \\
\text { counseling, early morning } \\
\text { appointments, thorough history } \\
\text { recording. } \\
\text { Complete dentures } \\
\text { Gag reflex management like } \\
\text { distraction and relaxation, home } \\
\text { exercises for practicing mandibular } \\
\text { movements, selective pressure final } \\
\text { impressions, hypotonic muscles affects } \\
\text { the musculature surrounding the } \\
\text { denture therefore one should not rely } \\
\text { on the musculature to aid in retention } \\
\text { and stability, non eugenol impression } \\
\text { materials for final impressions, use of } \\
\text { drugs like muscle relaxants at/or } \\
\text { during recording jaw relations, } \\
\text { decreased occlusal table, non-anatomic } \\
\text { or semi anatomic teeth with less cuspal } \\
\text { inclination, balanced occlusion, } \\
\text { custom modified teeth for facial } \\
\text { esthetics, minimal use of dentures, } \\
\text { simple and concrete instructions, } \\
\text { preservation of residual alveolar ridges } \\
\text { with more frequent follow ups. } \\
\text { Fixed partial and cast partial dentures } \\
\text { Use of more abutments, Heat cure } \\
\text { acrylic resin should be used for } \\
\text { temporary restorations, oral hygiene } \\
\text { maintenance program, use of metal } \\
\text { occlusal surfaces in definitive } \\
\text { restorations, use of implant whenever } \\
\text { indicated after thorough medical } \\
\text { checkup and patient consent. }\end{array}$} \\
\hline 2. & Patient communication & Hearing loss & Difficult to follow instructions & \\
\hline 3. & Endocrine & $\begin{array}{l}\text { Hyperthyroidism and } \quad \begin{array}{c}\text { hypothyroidism, } \\
\text { immunodeficiency (aggressive periodontitis) }\end{array}\end{array}$ & $\begin{array}{l}\text { Affects periodontium, alveolar } \\
\text { and basal bone metabolism }\end{array}$ & \\
\hline 4. & Esthetic & $\begin{array}{l}\text { Brachycephaly, raised upper lip, Mid-facial } \\
\text { hypoplasia, small nasal bridge, flat cranial base } \\
\text { (obtuse nasion-sella-basion angle), descending } \\
\text { angle of mouth, everted lower lip, unattractive } \\
\text { facial aesthetic movements. }\end{array}$ & $\begin{array}{l}\text { Facial form and profile, } \\
\text { selection of artificial teeth, } \\
\text { phonetics, low and high lip line }\end{array}$ & \\
\hline 5. & Maxillary arch & $\begin{array}{l}\text { Narrow and high palatal vault, reduced } \\
\text { maxillary sinus with concomitant reduction of } \\
\text { maxilla. }\end{array}$ & $\begin{array}{l}\text { Denture retention and stability, } \\
\text { facial esthetics }\end{array}$ & \\
\hline 6. & Mandibular arch & Hypoplasia & $\mathrm{Occ}$ & \\
\hline 7. & Neuro muscular & $\begin{array}{l}\text { Perioral and tongue muscle hypotonia, } \\
\text { protruded tongue, fissured lips and tongue, } \\
\text { tongue crenation, relative macroglossia (due to } \\
\text { anterior positioning of tongue), difficulty in } \\
\text { suckling, speech and mastication, abnormal } \\
\text { mandibular positioning (nonexisting mandibular } \\
\text { rest position at the end of the growth period), } \\
\text { dyskinesia (tongue thrusting, early } \\
\text { edentulousness), dystonia (abnormal jaw } \\
\text { movements, facial grimacing) }\end{array}$ & $\begin{array}{l}\text { Denture stability and retention, } \\
\text { phonetics and mastication with } \\
\text { artificial teeth, vertical } \\
\text { dimensions of occlusion and } \\
\text { rest, residual ridge resorption, } \\
\text { difficult to perform jaw relation } \\
\text { procedures, inability to follow } \\
\text { instructions. }\end{array}$ & \\
\hline 8. & Dentition & $\begin{array}{l}\text { Tooth agenesis (Central incisor > maxillary } \\
\text { lateral > incisor second premolars > mandibular } \\
\text { second premolar), delayed eruption, } \\
\text { microdontia, hypoplasia, taurodontism, mottled } \\
\text { teeth, thin enamel, supernumerary teeth and } \\
\text { hypodontia, mouth breathing, unstable } \\
\text { occlusion (cross bite, open bite, wear, } \\
\text { malocclusion, single interdental contact), }\end{array}$ & $\begin{array}{l}\text { Abutment selection for } \\
\text { removable and fixed partial } \\
\text { denture, halitosis after prosthesis } \\
\text { placement, difficult to develop } \\
\text { occlusion, difficult to institute } \\
\text { plaque control measures. }\end{array}$ & \\
\hline 9. & $\begin{array}{l}\text { Temperomandibular } \\
\text { joint and mandibular } \\
\text { movements }\end{array}$ & $\begin{array}{l}\text { Ligament laxity, unilateral or bilateral luxation, } \\
\text { loss of dental guidance for mandibular } \\
\text { movement, protrusive mandibular blockage, } \\
\text { absent lateral movements during mastication, } \\
\text { increased habitual mouth opening and increased } \\
\text { orofacial movement }\end{array}$ & $\begin{array}{l}\text { All jaw relation procedures are } \\
\text { dependent on proper mandibular } \\
\text { movement thereby in such cases } \\
\text { prosthesis cannot be fabricated } \\
\text { using adjustable articulators. }\end{array}$ & \\
\hline 10. & Treatment drugs & $\begin{array}{l}\text { Xerostomia, glossitis, candidiasis, stomatitis, } \\
\text { poor denture tolerance, unstable dentures, } \\
\text { denture trauma }\end{array}$ & $\begin{array}{l}\text { Crazing, dryness of prosthesis } \\
\text { material resulting in halitosis. }\end{array}$ & \\
\hline
\end{tabular}

\section{Discussion}

Cognitive impairment in patients with down's syndrome compounded with mild to moderate intellectual disabilities becomes more profound as the patient ages. This article presents a case of a patient with downs syndrome who was previously diagnosed with schizophrenia and was currently on medication for the same. Such cases have been described in the literature in the form of case reports, although there is little investigation done in finding the possible prevalence/link between 
schizophrenia and Down syndrome. According to Dykens et al, ${ }^{8}$ comparisons of psychiatric disorders in adolescents/young adults with downs syndrome were done with patients with other intellectual disabilities. They found $35 \%$ of those with downs syndrome had psychosis NOS (not otherwise specified) compared to $13 \%$ of those with other intellectual disabilities.

Considerable difficulties are encountered in diagnosing episodes of schizophrenia in downs syndrome patients because the standard criteria for diagnosis are not applicable. One such example was studied by Parasher, ${ }^{9} 2003$ and he found that abnormalities of thought and of psychotic experiences were difficult to elicit. Schizophrenia, to be diagnosed as a psychotic disorder requires few signs and symptoms to be present for a duration of six months, which include delusions, hallucinations, disorganized speech or behaviour, alogia, avolition and social and occupational dysfunctions. ${ }^{11}$ Current medications of patient was to treat symptoms of schizophrenia and had definite implications on the prosthodontic treatment. Side effects of Aripiprazole included hyper salivation, weight gain, trouble in swallowing and muscle spasm while Zuclopenthixol would result in sleepiness, orthostatic hypotension, akasthisia, dystonia, Xerostomia, abnormal voluntary movements and Parkinsonism. Although the patient was on drugs that would induce Xerostomia we found hypersalivation during routine prosthetic procedures.

Since patients with downs syndrome are routinely encountered by Prosthodontists for prosthetic rehabilitation, we reviewed the literature ${ }^{12-28}$ and compiled the prosthodontic implications along with possible solution and are summarised in Table 1. Major problems that have severely prosthodontic implicated in patients with Down syndrome are related to neuromuscular function. Muscle hypotonia, orofacial dyskinesia and dystonia hamper jaw relation prosthodontic procedures and every problem is individual in nature, therefore possible solutions and modifications will be individual.

\section{Conclusion}

The present case describes a case of Schizophrenia in a patient with downs syndrome. The patient was under the medication regimen for symptoms of Schizophrenia. Patience on the part of the prosthodontist is key to manage such cases successfully.

\section{Acknowledgements}

The authors would like to acknowledge the efforts by the patient and her caretaker for demonstrating excellent cooperation during the routing procedures of complete denture fabrication.

\section{References}

1. Conor WO. "John Langdon Down: The Man and the Message". Down Syndrome Research and Practice. 1999;6 (1): 19-24

2. Haliza T, Normastura AR, Azizah Y. Dental anomalies and oral hygiene status of Down syndrome children. Int J Public Health Clin Sci 2015; 2(3): 33-44.

3. Collacott RA, Cooper SA, McGrother C. Differential rates of psychiatric disorders in adults with Down's syndrome compared with other mentally handicapped adults. $\mathrm{Br} \mathbf{J}$ Psychiatry. 1992; 161:671-4.

4. Warren AC, Holroyd S, Folstein MF. Major depression in Down's syndrome. B J Psychiatry. 1989; 155:202-5.

5. Friedlander AH, Marder SR. The psychopathology, medical management and dental implications of schizophrenia. J Am Dent Assoc. 2002; 133(5):603-610.

6. Yaltirik M, Kocaelli H, Yargic I, Yaltirik M, Kocaelli H, Yargic I. Schizophrenia and dental management: review of the literature. Quintessence Int. 2004;35(4):317-320.

7. Myers BA and Pueschel SM. Brief Report: A Case of Schizophrenia in a population with Down Syndrome. Journal of Autism and Developmental Disorders, 1994; 24(1): 95-96

8. Dykens EM, Shah B, Davis B, Baker C, Fife T, Fitzpatrick J. Psychiatric disorders in adolescents and young adults with Down's 
syndrome and other intellectual disabilities. J Neurodev Disord. 2015; 7:9.

9. Prasher V P. Prevalence of psychiatric disorders in adults with Down's syndrome. Eur J Psychiatry 1995; 9: 77-82.

10. Prasher V P. Neuropsychological assessments of dementia in Down's syndrome and intellectual disabilities, 2nd Ed, 2018

11. American Psychiatric Association. Diagnostic and Statistic Manual of Mental Disorders, 4th ed. Washington DC: American Psychiatric Association 1994

12. Hennequin M, Faulks D, Veyrune JL and Bourdiol P. Significance of oral health in persons with Down's syndrome: a literature review. Developmental Medicine and Child Neurology 1999; 41: 275

13. Shapiro BL, Gorlin RJ, Redman RS and Bruhl HH. The palate and Down's syndrome. New England Journal of Medicine, 1967; 276: 1460.

14. Hoyer $\mathrm{H}$ and Limbrock G. Oro facial regulation therapy in children with Down's syndrome using the methods and appliances of Castillo-Morales. Journal of Dentistry for Children 1990;57: 442

15. Mason $\mathrm{R}$ and Profitt $\mathrm{W}$. The tongue thrust controversy: background and recommendations. Journal of Speech and Hearing Disorders, 1974; 39: 115

16. Limbrock G, Fischer Brandies $\mathrm{H}$ and Avalle C. Castillo-Morales orofacial therapy: treatment of 67 children with Down's syndrome. Developmental Medicine and Child Neurology, 1991; 33: 296

17. Kavanagh K, Kahane J and Kordan B. Risks and benefits of adenotonsillectomy for children with Down's syndrome. American Journal of Mental Deficiency, 1986; 91: 22

18. Glatznoll E and Berg R. Oral dysfunction in children with Down's syndrome: an evaluation of treatment effects by means of video registration. European Journal of Orthodontics, 1991; 13: 446

19. Haw C, Barnes T, Clark K, Crichton P and Kohen D. Movement disorder in Down's syndrome: a possible marker of the severity of mental handicap. Movement Disorders, 1996; 11: 395

20. Carlstedt K, Dahlhof G, Nilsson B and Modeer T. Effect of palatal plate therapy in children with Down's syndrome: A one-year study. Acta Odontologica Scandinavica, 1996;54: 122

21. Munetz M and Benjamin S. How to examine patients using the abnormal involuntary movement scale. Hospital and Community Psychiatry, 1988; 39: 1172

22. Reuland-Bosma W and Van Dijk L. Periodontal disease in Down's syndrome: a review. Journal of Clinical Periodontology, 1986; 13: 64

23. Dinan $\mathrm{T}$ and Golden T. Orofacial dyskinesia in Down's syndrome. British Journal of Psychiatry, 1990; 157: 131

24. Rogers D, Karki C, Bartlett C and Pocock P. The motor disorders of mental handicap: An overlap with the motor disorders of severe psychiatric illness. British Journal of Psychiatry, 1999;158: 97

25. Lavigne G, Goulet JP, Morrison F and Montplaisir JY. Le bruxisme, un vieux probleme vu sous une perspective nouvelle. Realite Âs Cliniques, 1994; 5: 199

26. Scully C, Cawson RA Medical problems in dentistry 4th ed: Wright, 1998

27. Tani H, Uchida H, Suzuki T, Shibuya Y, Shimanuki H, Watanabe $\mathrm{K}$ et al Dental conditions in inpatients with schizophrenia: A large-scale multi-site survey BMC Oral Health 2012; 12 : 32

28. Royal Australian and New Zealand College of Psychiatrists clinical practice guidelines for the treatment of schizophrenia and related disorders Australian and New Zealand Journal of Psychiatry 2005; 39 (1-2): $1-30$. 